\title{
Singularidades da formação em organização da cultura no Brasil
}

\author{
Singularities of skills development in \\ organization of culture in Brazil
}

Singularidades de la formación en
organización de la cultura en el Brasil

Antonio Albino Canelas Rubim

- Professor titular da Universidade Federal da Bahia (UFBA)

- Docente do Programa Multidisciplinar de Pós-Graduação em Cultura e Sociedade

- Membro do Centro de Estudos Multidisciplinares em Cultura

- Pesquisador I-A do CNPq

- Ex-presidente do Conselho Estadual de Cultura da Bahia

- Ex-diretor da Faculdade de Comunicação e do Instituto de Humanidades,

Artes e Ciências Professor Milton Santos, da UFBA.

•rubim@ufba.br 
O texto traça um panorama sobre a formação em organização da cultura e analisa mais detidamente o caso brasileiro e suas singularidades, entendendo que em nosso país este campo engloba os estudos em políticas culturais, gestão cultural e produção cultural.

PALAVRAS-CHAVE: FORMAÇÃO EM CULTURA • ORGANIZAÇÃO EM CULTURA • POLÍtICAS CULTURAIS • GESTÃO CULTURAL • PRODUÇÃO CULTURAL

\section{Abstract}

The text outlines the scenario of skills development in organization of culture, and analyzes in more detail the Brazilian case and its singularities, with the understanding that in our country this field encompasses studies of cultural policies, cultural management and cultural production.

KEYWORDS: SKILLS DEVELOPMENT IN CULTURE - ORGANIZATION OF CULTURE - CULTURAL POLICIES • CULTURAL MANAGEMENT • CULTURAL PRODUCTION

\section{Resumen}

El texto traza un panorama sobre la formación en organización de la cultura y analiza con mayor detenimiento el caso brasileño y sus singularidades. Se entiende que en nuestro país este campo engloba los estudios sobre políticas culturales, gestión cultural y producción cultural.

PALABRAS CLAVE: FORMACIÓN EN CULTURA • ORGANIZACIÓN DE LA ULTURA • POLÍTICAS CULTURALES • GESTIÓN

CULTURAL・PRODUCCIÓN CULTURAL 
O bonito nas pessoas

é que elas ainda não foram terminadas

Guimarães Rosa

Otem tema da formação de profissionais dedicados à organização da cultura, entendida como abrangendo as políticas, a gestão e a produção culturais, apresenta-se hoje como revestido de fundamental importância para o desenvolvimento da cultura e de políticas culturais criativas e contemporâneas. Uma discussão mais aprofundada da temática requer uma reflexão, ainda que panorâmica, das conformações da cultura na atualidade; do lugar da organização na configuração da vida cultural; e das singularidades da circunstância brasileira nesta esfera.

\section{CONFORMAÇÃO E ATUALIDADE DO CAMPO DA CULTURA}

A modernidade faz emergir a autonomização (relativa, é claro) do campo cultural em relação a outras esferas societárias, notadamente a religião e a política. Tal processo - que não pode ser confundido com isolamento social - implica a constituição da cultura como campo social singular, que articula e inaugura instituições, profissões, linguagens, símbolos, valores e tensões. A partir daí a cultura passa a ser nomeada e percebida como dimensão social determinada que pode ser estudada em sua especificidade. Cabe lembrar que um campo cultural exige crescentemente que sejam formados indivíduos para as novas profissões associadas às instituições que funda.

É possível imaginar alguns grandes eixos que perpassam o campo cultural desde a modernidade e, assim, produzem sua feição contemporânea. Simultânea à sua autonomia relativa, acontece uma politização da cultura. Isto é, a cultura, em conjunto com outras esferas sociais, passa a ter significado para uma política que deixa de ser legitimada pela referência ao transcendente, subsumido ao mundo das religiões. O Estado moderno e seu governo têm uma legitimação secular e uma predisposição laica. A cultura torna-se uma das fontes significativas dessa legitimidade. Paulatinamente tal legitimação secular passa a ser construída por meio de expedientes democráticos, que implicam disputa de hegemonias. Ou seja, consenso em lugar de mera coerção, típica de situações autoritárias. Ao recorrer à lógica da construção de hegemonias, a política necessariamente se articula com a cultura, posto que se trata da elaboração e da disputa de visões de mundo, nas quais política e cultura sempre estão imbricadas.

Na passagem da modernidade para o mundo contemporâneo, outro dispositivo perpassa e marca de modo relevante o campo cultural: a mercantilização da cultura, intimamente associada ao desenvolvimento das chamadas "indústrias culturais". Tal processo indica, sem mais, o avanço do capitalismo sobre os 
bens simbólicos. Estes bens encontravam-se preservados de serem produzidos por uma lógica submetida ao capital. A emergência das indústrias culturais faz com que os bens simbólicos não sejam produzidos como, também, mercadorias, porque capturados apenas na esfera da circulação, mas que já sejam concebidos como mercadorias no momento mesmo da produção. Com a mercantilização potencializa-se a tecnologização da cultura, a proliferação das mídias e o aparecimento da cultura midiática, como componente vital da circunstância cultural, em especial dos séculos XX e XXI.

Outro dispositivo essencial para a compreensão da cultura é a culturalização da política. Aos "clássicos" temas da política moderna - Estado; governos (executivo, legislativo e judiciário); monopólio da violência legal; direitos civis; liberalismo econômico etc. - a partir do século XX são agregadas novas demandas político-sociais, muitas delas de intenso teor cultural. Temas como ecologia, questão feminina, orientação sexual, modos de vida, comportamentos, diferenças étnicas, religiosas e nacionais, diversidade cultural; valores sociais, entre outros, são incorporados ao dia a dia da política e compõem programas dos partidos políticos, políticas governamentais e reivindicações da sociedade civil. Enfim, tornam-se parte viva do universo da política.

Mais um expediente pode ser destacado no processo de constituição da cultura contemporânea. Trata-se da culturalização da mercadoria, processo tão bem assinalado em estudos recentes acerca das chamadas "economia e indústrias criativas". Neste âmbito, cabe registrar o crescente papel de componentes simbólicos na determinação do valor das mercadorias, inclusive bens materiais. Tais componentes simbólicos - de denso conteúdo cultural - hoje também penetram e investem bens materiais. Com a culturalização da mercadoria, amplia-se mais uma vez e de modo intenso o lugar da cultura no mundo atual.

A cultura contemporânea se vê constituída e perpassada, igualmente, por fluxos e estoques culturais de tipos diferenciados. De um lado, o processo de globalização ou mundialização da cultura conforma produtos que, fabricados de acordo com padrões simbólicos desterritorializados, buscam se posicionar em um mercado mundial de imensas dimensões controlado pelos megaconglomerados, oriundos de gigantescas fusões de empresas, que associam cultura, comunicação, entretenimento e lazer. De outro lado, reagindo a esse processo de globalização, brotam em inúmeros lugares manifestações marcadas por fluxos e estoques culturais locais. Assim, o panorama contemporâneo aponta para um desigual e combinado processo de "glocalização" da cultura. Tal processo se torna ainda mais complexo porque perpassado na atualidade por novos fluxos regionais e nacionais. A vida "glocal" é também o mundo da emergência das regiões conformadas no interior de uma determinada nação ou entre nações. Os blocos supranacionais são exemplos emblemáticos disto. Também o nacional se reinventa e marca a contemporaneidade. 
Certamente outros dispositivos poderiam ser acionados para uma compreensão fina das configurações da cultura no mundo atual. A escolha desses eixos decorre do registro destacado ocupado por eles na conformação da cultura e de seu campo. Para concluir, pode-se afirmar que tais dispositivos fazem que a cultura passe a ter um lugar societário singular e expansivo na atualidade. A cultura, além de ser um campo social específico, transborda tais limites e adquire uma transversalidade que perpassa toda complexa sociabilidade contemporânea. Por conseguinte, as políticas culturais têm que dar conta do seu campo social específico e dessa transversalidade que faz a cultura permear os mais diferentes campos da sociabilidade atual e interagir cada vez mais com eles.

\section{O SISTEMA CULTURAL E SEUS COMPONENTES}

Traçado esse contexto, por certo panorâmico, a análise deve prosseguir buscando compreender a complexidade da cultura na atual circunstância societária.

De imediato, pode-se enumerar um conjunto de momentos como imprescindíveis para a existência e desenvolvimento do campo cultural hoje. Essa lista pode ser composta por movimentos como: 1. Criação, invenção e inovação; 2. Divulgação, transmissão e difusão; 3. Troca, intercâmbio e cooperação; 4. Preservação e conservação; 5. Análise, crítica, estudo, investigação, pesquisa e reflexão; 6. Formação; 7. Consumo; e 8. Organização. Sem considerar a presença de cada um desses momentos - e da articulação e qualidade deles - não se pode, a rigor, falar em uma efetiva vida cultural, pois a conformação do sistema implica a presença essencial de cada um desses momentos e movimentos. Sem tal concepção dificilmente pode-se pensar em políticas culturais, pois elas estão sempre e sistematicamente associadas a todos esses componentes da cultura.

Por certo, em uma sociedade não complexa, esses momentos e movimentos encontram-se associados e mesmo conjugados em uma mesma instituição ou um mesmo ator social. Entretanto, a complexidade própria do mundo contemporâneo implica a crescente diferenciação desses momentos e movimentos, configurando zonas de competência, instituições e atores com papéis especializados.

Os criadores, inventores e inovadores, representados por artistas, cientistas e intelectuais, vinculados aos universos culturais acadêmicos ou populares, muitas vezes são tomados como estrelas centrais do sistema cultural, dada a sua relevância como inauguradores de ideários, práticas e bens culturais. Ou seja, por sua admirável capacidade e mesmo genialidade em renovar a cultura. Mas, apesar desse papel primordial para o itinerário da cultura, não existe sistema sem que outros momentos, instituições e atores estejam contemplados e acionados. 
Os professores e comunicadores, inscritos em diversas ambientações e instituições sociais, são os principais tradutores dos momentos de divulgação, transmissão e difusão da cultura, ainda que outros atores e instituições possam realizar tais movimentos de modo secundário. Esses dispositivos são vitais para a democratização da cultura.

Também os momentos de preservação e conservação, atribuídos em especial aos museus, de todos os tipos, são essenciais para manter a herança cultural e democratizar o patrimônio cultural acumulado, seja ele material ou imaterial. Cuidar do patrimônio - tangível e intangível - é fundamental para a memória, o desenvolvimento e a identidade dos agrupamentos humanos. Não por acaso, o tema do patrimônio sempre teve um peso relevante nas políticas culturais no âmbito internacional e no Brasil.

Para além de ser preservada e conservada, uma cultura precisa, sob pena de estagnação, interagir com outras culturas, por meio de dispositivos de distribuição, circulação, troca, intercâmbio e cooperação. Sem esse permanente processo de "negociação" cultural, deliberadamente instituído e estimulado, a cultura tende a perder seu dinamismo vital. Por óbvio, existem diferenciados tipos de trocas, as quais afetam de maneira diversa as culturas. Em polos opostos, as trocas podem ser equânimes ou profundamente desiguais. A depender desse caráter elas podem ser altamente benéficas ou provocar graves prejuízos. Apesar disso, as trocas são essenciais para a vida das culturas.

Um sistema cultural não pode ter vigência sem que a cultura (criada, difundida, preservada e intercambiada) seja submetida ao crivo da discussão e avaliação públicas. Essa função de reflexão sobre a cultura é destinada aos analistas, críticos, estudiosos, investigadores e pesquisadores. A discussão anima a vida cultural; legitima, questiona e desqualifica ideias, práticas e valores; possibilita trocas culturais. Enfim, é parte igualmente indispensável à dinâmica viva da cultura. A liberdade, a possibilidade de discussão e a efetiva avaliação estão intimamente associadas ao aprimoramento da cultura.

A cultura necessita de ter profissionais qualificados. Nesta perspectiva, a formação de pessoal para o campo cultural torna-se essencial. Sem uma formação adequada de pessoal - profissional ou não -, a esfera cultural fica bastante fragilizada. Um sistema cultural não pode prescindir de pessoal competentemente formado.

A esfera do consumo, ato imprescindível para a completude do circuito cultural, tem como sua singularidade ser sempre uma esfera não profissionalizada, muitas vezes a única em todo o ciclo sociodinâmico da cultura. A não-profissionalização, entretanto, não afeta de modo algum o status do consumo. Pelo contrário, indica a amplitude e mesmo a universalidade do ato de recepção da cultura. Todos os cidadãos são potencialmente consumidores da cultura, quando ela não está subordinada a uma lógica mercantil, que restringe o con- 
sumo somente a uma troca monetária ou não funciona como elemento de exclusão. Sem o consumo, em seu sentido mais amplo, a cultura não se realiza: permanece incompleta. Nesta perspectiva, todos os indivíduos estão imersos em ambientes culturais ainda que em modalidades muito desiguais de acesso pleno aos seus estoques e fluxos. Mesmo o consumo, talvez a esfera mais larga de participação, pode ser obstruído por requisitos econômicos, sociais e educacionais que limitam tal acesso. Mas de diferentes maneiras e graus, todos vivem um ambiente cultural, em menor ou maior intensidade.

Por fim, para abranger todo o sistema cultural resta um outro momento, por vezes esquecido. Certamente um movimento de mais difícil percepção. E, talvez por isso, uma das regiões mais recentemente traduzidas em instituições e profissões dentro do campo cultural. Essa área pode ser nomeada como organização da cultura. Claro que, de algum modo, todos os momentos anteriores implicam aspectos organizativos, mas neste caso precípuo o que ocupa o centro do jogo é a organização mesma do campo cultural: seja em um patamar macro, como nas políticas culturais; seja em um horizonte micro, como em determinados eventos culturais.

Depois dessa trajetória percorrida, cabe agora nos determos na organização da cultura, dada sua interseção com o tema investigado.

\section{A ORGANIZAÇÃO DA CULTURA E SUAS DENOMINAÇÕES}

Desnecessário reafirmar que a organização é um momento imanente ao sistema e mesmo a toda e qualquer manifestação e expressão culturais, em um patamar macro e/ou microssocial. Não existe cultura sem seu momento organizativo. Mesmo determinadas manifestações culturais ditas espontâneas não podem se realizar sem organização. Mas esse caráter inerente e "natural" talvez tenha obscurecido a imediata atenção a esse movimento, que só recentemente emergiu como espaço de práticas e formulações.

Uma das características dessa emergência recente e, por conseguinte, da ausência de tradição na conformação específica desse momento é a falta de sedimentação até na sua nomeação. Denominações as mais distintas são acionadas para intitular o momento da organização da cultura e os profissionais responsáveis por seu tratamento. Assim, a denominação de gerentes e administradores culturais predomina nos Estados Unidos e na França; a noção de animadores e promotores culturais possui uma importante tradição na Espanha; em muitos países da América Latina fala-se em trabalhadores culturais; e em outros países podem ser utilizados termos como mediadores culturais, engenheiros culturais ou cientistas culturais (OEI, 1998, p. 19-20). Em Portugal, também se aciona a expressão programadores culturais para dar conta da esfera da organização da cultura (madeira, 2002). Mas recentemente a noção de gestão cultural vem ganhando grande vigência em diversos países, inclusive ibero-americanos: 
La noción de gestión cultural ingresa al discurso cultural en Iberoamérica con bastante influencia hacia la segunda mitad de la década de los ochenta, tanto en las instituciones gubernamentales como en los grupos culturales comunitarios (OEI, 1998, p. 19).

A pluralidade de denominações não só indica a idade recente das práticas e dos estudos acerca da organização da cultura, mas sugere pensar em itinerários e peculiaridades nacionais no desenvolvimento do tema, com forte incidência sobre a formação de seus profissionais. Acompanhar tais trajetórias distintas pode servir para iluminar e dar continuidade à análise em curso.

\section{SINGULARIDADE BRASILEIRA DA ORGANIZAÇ̃̃O DA CULTURA}

O caso brasileiro apresenta, nessa perspectiva, uma notável singularidade, pois a noção predominante tem sido a de produção cultural, pelo menos até recentemente. Tal dominância pode ser observada na nomeação dos primeiros cursos brasileiros dedicada à área de organização da cultura ${ }^{1}$ e do modo mais usual de (auto)nomeação dos profissionais que trabalham nessa área. Por exemplo, na dissertação de Maria Helena Melo da Cunha (2005) sobre o tema, os nove profissionais que prestaram depoimentos sobre a construção de seu campo de trabalho na cidade de Belo Horizonte na imensa maioria das vezes utilizavam a denominação produtores culturais. Só excepcionalmente se reconheceram na expressão gestão cultural, apesar da clara adesão da autora a este último termo, inclusive no título do trabalho - Gestão cultural: profissão em formação.

A opção por essa denominação decorre obviamente das peculiaridades históricas, em especial as relativas às políticas culturais implementadas no país. Políticas culturais de caráter mais sistemático foram inauguradas desde a década de 1930, em especial com a gestão de Mário de Andrade no Departamento de Cultura da Prefeitura de São Paulo e com a criação do Serviço do Patrimônio Histórico e Artístico Nacional (Sphan) e de outras instituições culturais no primeiro Governo Vargas (1930-1945),. Apesar disso, o Brasil não desenvolveu, entre essas políticas, uma preocupação mais abrangente com a formação de pessoal na área de organização da cultura. Desse modo, não se constituiu, infelizmente, uma tradição que fizesse emergir no país a gestão cultural como campo específico de atenção do Estado nacional. A preocupação com a formação foi não-sistemática e apenas momentânea, como aconteceu com o Plano de Ação Cultural da Ditadura Militar². Além disso, ela nem sempre se tornou efetiva.

1 Os cursos de Produção Cultural da Universidade Federal Fluminense (UFF) e da Universidade Federal da Bahia (UFBA), ambos instalados em meados da década de 1990. Posteriormente é que surgiram no Brasil cursos intitulados de Gestão Cultural.

Cf. Calabre (2007). 
Na segunda metade dos anos 1980, com o predomínio da visão neoliberal e a chamada "crise do Estado" e sua retração, o Governo José Sarney, de maneira contraditória, ampliou a infraestrutura cultural, inclusive com a criação do Ministério da Cultura em 1985. Simultaneamente, com a Lei Sarney (1986), deslocou o financiamento da cultura para a iniciativa privada, de modo muito particular. Recorrendo a uma política de leis de incentivo, o Estado abre mão de impostos para estimular o setor privado a investir na cultura. Dessa maneira, o recurso é estatal, mas as decisões passam a ser do setor privado. Essa alteração do vinculo entre Estado e cultura ocasiona uma mutação acentuada no sistema cultural brasileiro, ainda não estudada em toda a sua plenitude.

Uma lógica de financiamento do setor empresarial se impõe, obrigando, para o mal e/ou para o bem, a emergência de "intermediários culturais", como serão chamados na Lei Rouanet, em sua revisão acontecida no Governo FHC - Francisco Weffort. Tais "intermediários” devem elaborar projetos, captar recursos, efetivar eventos etc. Em suma, são "produtores" que devem organizar a cultura, não adstrita ao Estado. Este se encontra quase paralisado, sem recursos e sem políticas culturais. As leis de incentivo tornam-se mesmo as políticas culturais do Governo Fernando Henrique Cardoso, com Francisco Weffort ${ }^{3}$. Não por acaso, pode-se facilmente constatar que a formação do mercado de trabalho da área de organização da cultura, pelo viés de produtores culturais, acontece a partir da segunda metade dos anos 1980 e se amplia nos anos 1990.

A ausência de tradição na formação de gestores,a submissão da cultura à lógica de mercado e a fragilidade das políticas culturais do Estado nacional acentuada nos oito anos de Fernando Henrique Cardoso e Francisco Weffort - configuram, por excelência, o contexto elucidativo da emergência da denominação de produtores culturais, com as características que eles adquirem no país. A explicação elaborada ilumina igualmente a importância que o marketing cultural obteve no Brasil contemporâneo, quando comparado com outros países latino-americanos ${ }^{4}$.

\section{DESAFIOS DA FORMAÇÃO EM ORGANIZAÇÃO DA CULTURA NO BRASIL}

As mutações recentes da cena das políticas culturais no Brasil sugerem alguma possibilidade de reversão dessa singularidade, porque o Estado nacional passou a ter um papel mais ativo no campo da cultura, implementando um conjunto efetivo de políticas culturais ${ }^{5}$. A existência de políticas culturais nacionais é condição necessária, mas não suficiente, para a reversão dessa perversa singu-

3 Sobre o tema, consultar Castello (2002, p. 627-656); e Rubim, A. (2007, p. 11-36).

4 Sobre marketing cultural, ver Rubim, A. (2007, p. 53-77).

5 Para uma análise dessas políticas, consultar Rubim, A. (2007; 2008, p. 51-74; 2010). 
laridade. O fato é que ela exige não só uma política nacional de fortalecimento das políticas e gestão públicas da cultura, mas também uma política sistemática de formação de organizadores da cultura, especialmente de formuladores de políticas e gestores culturais.

No entanto, até recentemente, o atual Ministério da Cultura não havia demonstrado sensibilidade com relação ao tema da formação de pessoal em cultura. Um exemplo significativo é a publicação do "Programa cultural para o desenvolvimento do Brasil”, editado em 2006, com o duplo caráter de relatório do primeiro mandato e de programa para o segundo, no qual o assunto quase não é tratado (MC, 2006). Outro exemplo relevante é o documento inicial do "Plano nacional de cultura" (MC, 2007) Neste, o tema da formação, apesar de ser citado 23 vezes nas suas 85 páginas, encontra-se completamente diluído nas mais diferentes áreas da cultura, não contemplando um programa integrado na área de formação. Com relação à qualificação em organização da cultura, a situação é bem mais grave, pois ela, além da dispersão, só é citada nitidamente em duas ocasiões. Assim, mesmo nessa diluída atenção à formação, a organização da cultura é desconsiderada.

Só no ano 2009, no bojo da retomada da construção do Sistema Nacional de Cultura, o ministério passou a tratar mais detidamente do tema. Foram constituídas três comissões para desenvolver e dar subsídios ao Sistema Nacional de Cultura, sendo duas delas diretamente voltadas para o tema da formação. Uma tem como missão precípua a formulação de um projeto piloto de curso em gestão cultural já realizado e testado pelo ministério e que deve ser replicado em diferentes regiões do país. Uma outra comissão procedeu ao mapeamento de todas as iniciativas de formação em organização da cultura existentes no Brasil, fossem elas de graduação, pós-graduação ou extensão. $\mathrm{O}$ objetivo foi traçar um panorama da situação brasileira e detectar potenciais parceiros para a alvissareira constituição de uma rede de formação e qualificação em cultura, que envolva o ministério, além de secretarias estaduais e municipais de cultura. Tal rede pode se conformar como o primeiro investimento sistemático no sentido de formar pessoas nas áreas ligadas à cultura no Brasil.

A articulação dessas comissões com a construção do Sistema Nacional de Cultura indica o interesse em superar a antiga predominância dos produtores culturais, deslocando o foco da formação para os formuladores de políticas culturais e os gestores de cultura. Com isso, a singularidade brasileira derivada do momento de hegemonia neoliberal é colocada em cheque. O Estado reassume seu papel de formulador de políticas e para isso necessita formar gestores culturais. O Sistema Nacional de Cultura, para a sua implantação consistente e qualificada, precisa desses profissionais. Ele implica uma articulação e qualificação dos diferentes níveis estatais: nacional; estadual e municipal. Sem articulação e qualificação, o Sistema Nacional de Cultura dificilmente poderá ser implantado e se desenvolver de modo satisfatório. 
Urge, por conseguinte, que o ministério passe a enfrentar o tema da formação com a atenção e grandeza que ele exige. Encaminhamentos razoáveis para a questão podem ser a formulação e a realização do programa nacional de formação e qualificação em cultura, com base em um sistemático mapeamento da situação da capacitação no país. Por meio deste seriam diagnosticados os problemas e os potenciais existentes e, simultaneamente, identificados os possíveis parceiros para a construção conjunta da rede de formação. Além disso, o programa deve estar previsto de modo destacado e articulado no Plano Nacional de Cultura e funcionar como um dos pilares integrados ao Sistema Nacional de Cultura. Desse modo, o Brasil pode resolver em plenitude o dramático quadro da formação e da qualificação do pessoal dedicado à cultura, especialmente à sua organização.

\section{ALGUMAS PROPOSIÇÕES FINAIS}

Traçada em linhas gerais as peculiaridades da trajetória cultural brasileira, torna-se necessário aprofundar as relações entre políticas, gestão e produção culturais. Antes de tudo, é imprescindível afirmar a pertença das três noções ao registro de organização da cultura e, por conseguinte, a inevitável proximidade delas. Uma quase identidade, por certo. Nuances podem ser anotadas em uma observação mais refinada. Assim, pode-se sugerir alguma distinção fina - nem sempre realizada - na esfera da organização da cultura. É possível imaginar três níveis diferentes dessa esfera: a dos formuladores e dirigentes, afeitos ao patamar mais sistemático e macrossocial das políticas culturais; a dos gestores, instalados em instituições e/ou projetos culturais mais permanentes, processuais e amplos; e, finalmente, a dos produtores, mais adstritos a projetos de caráter mais eventual e microssocial. Cabe registrar que todos esses tipos de profissionais, sem privilégios, são imprescindíveis para que a organização da cultura aconteça de modo eficiente e criativo.

A distinção fina acima formulada, entretanto, não deve obrigar a uma especialização prematura na formação dos organizadores da cultura. O seu caráter recente indica, pelo menos na situação atual, trabalhar no sentido de formar profissionais que possam ter um desempenho satisfatório nas três vertentes anotadas. Mas as peculiaridades das trajetórias nacionais certamente influenciam sobremodo as configurações dos cursos em cada país e região do globo. A prevalência da denominação de produtores culturais no Brasil é um sintoma relevante da modalidade singular de constituição da esfera da organização da cultura em território nacional, indicando as potencialidades a serem reconhecidas e os entraves a serem criticados e superados ${ }^{6}$.

6 Uma discussão cuidadosa sobre a delimitação da figura do produtor cultural pode ser encontrada no trabalho de Linda Rubim (2005, p. 13-31) 
Antes de detalhar uma proposição de conteúdos programáticos, visando inclusive superar problemas detectados no panorama nacional, é necessário traçar um rápido quadro da formação na situação brasileira. De imediato, registre-se o pouco desenvolvimento dessa formação, em comparação com outros países, inclusive ibero-americanos, a exemplo da Colômbia, do México e da Espanha. Existe hoje, no país, uma gama dispersa de pequenos e esporádicos cursos de extensão, em geral de tempo limitado e sem uma formatação mais consistente. Quase todos são voltados à elaboração de projetos culturais e ao preenchimento de formulários destinados às leis de incentivo. existem alguns poucos cursos de graduação em universidades, nas áreas de produção e gestão culturais, sem quase nenhuma interação que possa servir para uma troca e uma construção coletiva de uma área sólida de formação graduada. Por fim, começam a aparecer algumas experiências em pós-graduação, quase sempre situados apenas no nível de especialização. Mas a acelerada expansão da área leva a pensar na possibilidade de uma rápida superação desse quadro de dificuldades, em especial se existirem políticas públicas voltadas para esta esfera essencial da cultura.

Em seguida, deve-se destacar o lugar ocupado, para o mal e/ ou para o bem, por características que têm marcado a área da organização da cultura no país, tais como: viés somente empresarial e mercantil; prevalência de uma concepção de eventos e de patamares de realização microssociais em detrimento de um olhar mais macrossocial, processual e público. Superar tais deficiências, sem desdenhar os aspectos positivos trazidos por esse itinerário, é certamente essencial para qualificar a formação na área da organização da cultura no Brasil.

Considerando as formulações elaboradas, a experiência internacional e as singularidades nacionais, é possível formatar um conjunto de conteúdos programáticos que alicercem a construção de uma formação qualificada e sintonizada com as dinâmicas culturais da sociedade contemporânea. Por certo, não se trata de uma receita possível, que seja replicada em todas as partes, pois a formação em cultura não pode nunca se esquecer que traços culturais singulares sempre mantêm substantiva conexão com territórios e suas circunstâncias sociais e políticas. Trata-se apenas de um exercício de imaginar conteúdos julgados relevantes para a formação em cultura. Mas a configuração efetiva da cada curso deriva da complexa interlocução assinalada e da sensível sintonia com suas circunstâncias.

Na perspectiva de sugerir alguns conteúdos considerados importantes, acredita-se que os temas a serem tratados na formação podem ser os seguintes: 1 . Teorias da cultura; 2. Cultura e sociedade; 3 . Contemporaneidade e dinâmicas "glocais" da cultura; 4. Manifestações das culturas locais, regionais, nacionais e globais; 5. Culturas e identidades; 6. Diversidade cultural; 7. Estudos da cultura; 8. Leitura e crítica dos bens culturais; 9. Políticas culturais (inclusive legislação e direitos culturais); 10. Cultura e desenvolvimento (sustentável); 11. 
Gestão e administração da cultura; 12. Economia da cultura; 13. Orçamento e finanças em cultura; 14. Elaboração de projetos em cultura; 15. Produção cultural; 16. Divulgação e marketing culturais; 17. Cooperação e intercâmbio culturais; 18. Redes culturais; 19. Consumo, públicos e mercados culturais; 20. Criatividade e cultura; 21 . Pesquisa em cultura; 22 . Seminários de temas atuais em cultura e 23 . Oficinas temáticas em cultura.

Em suma: uma sólida formação político-cultural global-local; uma forte sensibilidade para a diversidade cultural; um ativo compromisso com a justiça e equidade sociais; uma predisposição para a criatividade, a iniciativa e a inovação; uma atitude proativa; e uma boa capacidade organizativa.

Além desses aspectos de conteúdo, atenção especial deve ser dada no curso a aspectos acadêmico-pedagógicos, tais como: 1. Interação frequente entre teorias, análises, informações, práticas e experimentos; 2 . Adequação entre conteúdos, formatos e procedimentos pedagógicos; 3. Modalidades de avaliação pertinentes; e 4. Abertura para intenso e rico intercâmbio com as circunstâncias sociais e culturais e com a contemporaneidade.

\section{REFERÊNCIAS}

CALABRE, Lia. A ação federal na cultura: o caso dos conselhos. 0 Público e o Privado. Fortaleza, v. 9, n. 63, jan./jun. 2007. CUNHA, Maria Helena Melo da. Gestão cultural: profissão em formação. 2005. Dissertação (Mestrado em Educação) - Faculdade de Educação da Universidade Federal de Minas Gerais, Belo Horizonte.

CASTELLO, José. Cultura. In: LAMOUNIER, Bolívar; FIGUEIREDO, Rubens (Org.). A era FHC: um balanço. São Paulo: Cultura, 2002.

MADEIRA, Cláudia. Os novos notáveis: os programadores culturais. Oeiras: Celta, 2002.

MC - MINISTÉRIO DA CULTURA. Programa Plano nacional de cultura: diretrizes gerais. Brasília: Ministério da Cultura / Câmara dos Deputados, 2007.

Programa cultural para o desenvolvimento do Brasil. Brasília: Ministério da Cultura, 2006.

OEI - ORGANIZAÇÃO DOS ESTADOS IBERO-AMERICANOS. Cuadernos Cultura I. Conceptos básicos de administración y gestión cultural. Madrid: OEI, 1998.

RUBIM, Antonio A. Canelas (Org.). Políticas culturais no Governo Lula. Salvador: Edufba, 2010.

Políticas culturais do Governo Lula - Gil: desafios e enfrentamentos. In: RUBIM, Antonio A. Canelas; BAYARDO, Rubens (Org.). Políticas culturais na Ibero-América. Salvador: Edufba, 2008.

Políticas culturais no Brasil: tristes tradições, enormes desafios. In: RUBIM, Antonio A. Canelas; BARBALHO, Alexandre (Org.). Políticas culturais no Brasil. Salvador: Edufba, 2007.

Marketing cultural. In: RUBIM, Linda (org.) Organização e produção da cultura. Salvador, EDUFBA, 2005.

RUBIM, Linda. Produção cultural. In: RUBIM, Linda (org.) Organização e produção da cultura. Salvador: Edufba, 2005. 